\title{
Behaviour of cranes (family Gruidae) mirrors their phylogenetic relationships
}

\author{
Nela Nováková* (i] and Jan Robovský (i)
}

\begin{abstract}
Background: The behavioural repertoire of every species evolved over time and its evolution can be traced through the phylogenetic relationships in distinct groups. Cranes (family Gruidae) represent a small, old, monophyletic group with well-corroborated phylogenetic relationships on the species level, and at the same time they exhibit a complex and well-described behavioural repertoire.

Methods: We therefore investigated the evolution of behavioural traits of cranes in a phylogenetic context using several phylogenetic approaches and two types of trait scoring. The cranes exhibit more than a hundred behavioural displays, almost one third of which may be phylogenetically informative.

Results: More than half of the analysed traits carry a significant phylogenetic signal. The ancestor of cranes already exhibited a quite complex behavioural repertoire, which remained unchanged in Balearicinae but altered greatly in Gruinae, specifically by the shedding of traits rather than their creation. Trait scoring has an influence on results within the Gruinae, primarily in genera Bugeranus and Anthropoides.

Conclusions: Albeit the behavioural traits alone cannot be used for resolving species-level relationships within the Gruidae, when optimized on molecular tree, they can help us to detect interesting evolutionary transformations of behaviour repertoire within Gruiformes. The Limpkin (Aramus guarauna) seems to be the most enigmatic species and should be studied in detail for its behavioural repertoire, which may include some precursors of crane behavioural traits.
\end{abstract}

Keywords: Ancestral behavioural repertoire, Evolution, Phylogenetic signal

\section{Background}

Behavioural traits have been traditional sources of phylogenetic information along with morphological data (de Queiroz and Wimberger 1993; Kusmierski et al. 1997; Gatesy et al. 1999), even though a behavioural repertoire was often believed to be highly adaptive. Currently, behavioural data together with morphological data are being replaced by much more extensive molecular data, which exhibit lower rates of homoplasy and better tree resolution due to a higher number of informative characters (Scotland et al. 2003). Additionally, molecular

*Correspondence: novakn01@jcu.cz

Faculty of Science, University of South Bohemia, Branišovská 1760,

37005 České Budějovice, Czechia methods have been routinely applicable and have become much cheaper, while the complete description of the behavioural repertoire requires months and years of effort, and the homology of some traits remains uncertain. The use of behavioural data combined with phylogenetic analysis has decreased in recent years (Price et al. 2011). Nevertheless, this combination of behavioural data and phylogenetic analysis allows us to study the evolution of behaviour in a phylogenetic context and thus, in the unprecedented detail the evolution of specific behavioural traits or the whole repertoire (Senter 2008; Duda and Zrzavý 2013; Lister 2014; Ligon et al. 2018; Ericson et al. 2020).

It is already documented that behaviour often carries significant phylogenetic signal (Prum 1990; de Queiroz original author(s) and the source, provide a link to the Creative Commons licence, and indicate if changes were made. The images or other third party material in this article are included in the article's Creative Commons licence, unless indicated otherwise in a credit line to the material. If material is not included in the article's Creative Commons licence and your intended use is not permitted by statutory regulation or exceeds the permitted use, you will need to obtain permission directly from the copyright holder. To view a copy of this licence, visit http://creativecommons.org/licenses/by/4.0/. The Creative Commons Public Domain Dedication waiver (http://creativeco mmons.org/publicdomain/zero/1.0/) applies to the data made available in this article, unless otherwise stated in a credit line to the data. 
and Wimberger 1993; McLennan and Mattern 2001; Rendall and Di Fiore 2007; Scholes III 2008; Miles and Fuxjager 2019), which could allow behavioural traits to be used for supporting particular nodes as well, especially where data subsets produce conflicting support (Gatesy et al. 1999). Nevertheless, there is a strong inequality in majority of the works in the number of inspected behavioural traits compared to morphological or molecular data, as behavioural traits are rarely covered in datasets (Paterson et al. 1995; Kennedy et al. 1996; Blomberg et al. 2003; Ligon et al. 2018). Additionally, behavioural data allow us to reconstruct the ancestral behavioural repertoire for particular groups (Cap et al. 2002; Lister 2014), which is an important task if we are to understand how behaviour has evolved over time with regard to the homoplasy and adaptive potential of behaviour for the particular groups (Lefebvre et al. 2016; Downs et al. 2019; Penndorf and Aplin 2020). The behavioural traits have proven to be at least as good as the morphological data, for example in displays of manakins, which are completely congruent with their syringeal anatomy (Prum 1990). The usefulness of behaviour for phylogeny estimation was also supported by de Queiroz and Wimberger (1993), who combined and analysed multiple datasets against each other and found that morphological data did not prove to be better than behavioural. Similarly, as in the case of five genera in the Gasterosteidae fish family, where both morphological and behavioural data produced the same topology and the total evidence data provided a robust phylogeny (McLennan and Mattern 2001). Same results occurred in the case of toucans and barbets, it was proven that the body size can predict their mating behaviour and vice versa, and that mating behaviour can catalyse diversification (Miles and Fuxjager 2019).

We identified several promising groups for inspection of the evolution of behaviour in a phylogenetic context and comparison of behavioural traits with other data sets-for example, Anatidae (Lorenz 1941; Johnsgard 1962, 1965; Livezey 1991), Gruidae (for detail see below), Bovidae [e.g. Walther (1984) - for preliminary assessment see Vrba and Schaller (2000); Deleporte and Cap (2014)]. Some datasets have been analysed in pioneering works e.g. Felidae [Mattern and McLennan (2000), with potential additions of traits from Hemmer (1966); Leyhausen (1979); Sunquist and Sunquist (1996)], Macropodiformes (Ganslosser 1993, 1995); Pipridae (Prum 1990, 1994, 1998) - and could benefit from revising the phylogeny of specific groups associated with the denser taxa sampling and/or more (molecular) data available. Cranes (Gruidae) seemed to be excellent candidates for such detailed inspection of the evolution of behavioural traits in a phylogenetic context, as they represent a small, old group with well-corroborated phylogenetic relationships on the species level, and with a complex and well-described behavioural repertoire.

Specifically, cranes form a monophyletic group with the deepest separation between Balearicinae and Gruinae estimated at some 31-37 million years ago, with well-supported relationships among particular species (Gaubert et al. 2005; Krajewski et al. 2010; Krajewski 2019). Their closest relatives are the family Aramidae, then the family Psophiidae and the family Rallidae (Prum et al. 2015). Ellis et al. (1998) published a complete homologized sociogram of impressive and complex behaviour. Nevertheless, these unique data have neither been combined with molecular data for the detection of phylogenetic signals in a behavioural repertoire nor analysed for the evolution of specific behaviour traits under phylogenetic control.

Cranes are tall, omnivorous birds inhabiting wetlands and grasslands worldwide, except for Antarctica and South America, and number only 15 species (Johnsgard 1983). Eleven crane species are threatened with extinction, according to the IUCN Red list, including one species that is critically endangered, three species that are endangered, and six species that are vulnerable (Harris and Mirande 2013; IUCN 2021). Some of them migrate seasonally over great distances (e.g. Grus grus), some migrate only altitudinally (e.g. Grus paradisea), and some do not migrate (e.g. Balearica spp.), in conformity with ecological parameters of the inhabited regions (Johnsgard 1983; Prange 2016). All cranes are monogamous with stable pairs and lay a small clutch of no more than three eggs (Johnsgard 1983). The pairs are created and maintained through complex dances, accompanied by calls performed by both partners (Johnsgard 1983). Frequency of pair dances and thus harmonization of the pair affects their reproductive success (Takeda et al. 2019). Cranes also exhibit a system of social postures, displays, and other activities as feeding habits or alerts, made up of at least 60 behavioural characters (Ellis et al. 1998; Panov et al. 2010). Dances are usually completed with a vocalization. Archibald (1976) assumed phylogeny of cranes based on unison calls of different species and succeeded in dividing cranes into subfamilies Balearicinae and Gruinae and proposed three genera: Anthropoides, Grus, and Bugeranus. Besides pair dances, even unpaired subadults exhibit dancing behaviour. It is considered that dancing facilitates socialization and pair formation as displacement activity or play behaviour (Dinets 2013). Furthermore, certain displays may be related to dominance as performed by singletons in wintering flocks (Takeda et al. 2018). The closest relative of the family Gruidae is the Limpkin (Aramus guarauna), which is a snail specialist living in the wetlands of Florida, the Caribbean, 
and Central and South America (Fain et al. 2007). The behavioural repertoire of Limpkin is not well explored, although it is assumed that they show some crane-like displays (Bryan and Kirwan 2018). For the other outgroup, Purple Swamphen (Porphyrio porphyrio) was chosen. It belongs to the family Rallidae, which is sister clade to the Limpkin and crane lineages (Gong et al. 2017).

In this study we attempt to inspect the evolution of cranes in a phylogenetic context, using these approaches: (1) reconstruction of ancestral behavioural repertoire of all cranes and their particular groups and the identification of behavioural evolutionary novelties; (2) estimation of phylogenetic informativeness and phylogenetic signal in the behavioural repertoire of cranes using the phylogenetic control based on mitochondrial genomes; (3) comparison of the influence of various scorings of behavioural traits on reconstruction of ancestral behavioural repertoire and its phylogenetic informativeness.

\section{Methods}

\section{Behavioural data}

In this study, all 15 species of cranes recognised by all latest reviews (e.g. Johnsgard 1983; Harris and Mirande 2013; Prange 2016) were analysed (see names in Fig. 1, or in Additional file 1: Table S1). We used a complete sociogram from the study of Ellis et al. (1998) in which all behavioural traits observed in the cranes are specified and scored. The complete sociogram contains 107 behavioural traits, including vocalization (17 characters), agonistic displays (32 characters), and parental behaviour
(13 characters). As some behavioural traits are exhibited by all species or by only one species, the total number of possibly phylogenetically informative characters was 28 , composed of vocalization (2 characters), agonistic behaviour ( 23 characters), and pair-related behaviour (3 characters). Names of all inspected specific behavioural traits and their abbreviations are specified in Table 1; for a compressed description of individual traits, see Additional file 1: Table S1; the original data are presented in Ellis et al. (1998). The original scoring from the sociogram was accepted and transformed into a numerical matrix in this way: $0=$ absent, $1=$ occurring occasionally, $2=$ occurring regularly, $3=$ occurring often, $4=$ occurring very often, $\mathrm{NA}=$ undocumented. We also created a binary version of the matrix containing only information about the presence/absence of inspected traits (Additional file 1: Table S2).

\section{Genetic data}

To control behavioural traits for phylogeny, we used complete sequences of mitochondrial genomes of all 15 species of cranes (Krajewski et al. 2010) and available mitochondrial sequences for the Limpkin (Boast et al. 2019) and the Purple Swamphen which we used as the outgroups (Fain et al. 2007; García-R et al. 2014). Currently, the mitochondrial genome is the only genetic data source available for all crane species [Krajewski (2019); our inspection of GenBank database]. All the sequences were gathered from GenBank (https://www.ncbi.nlm.nih.

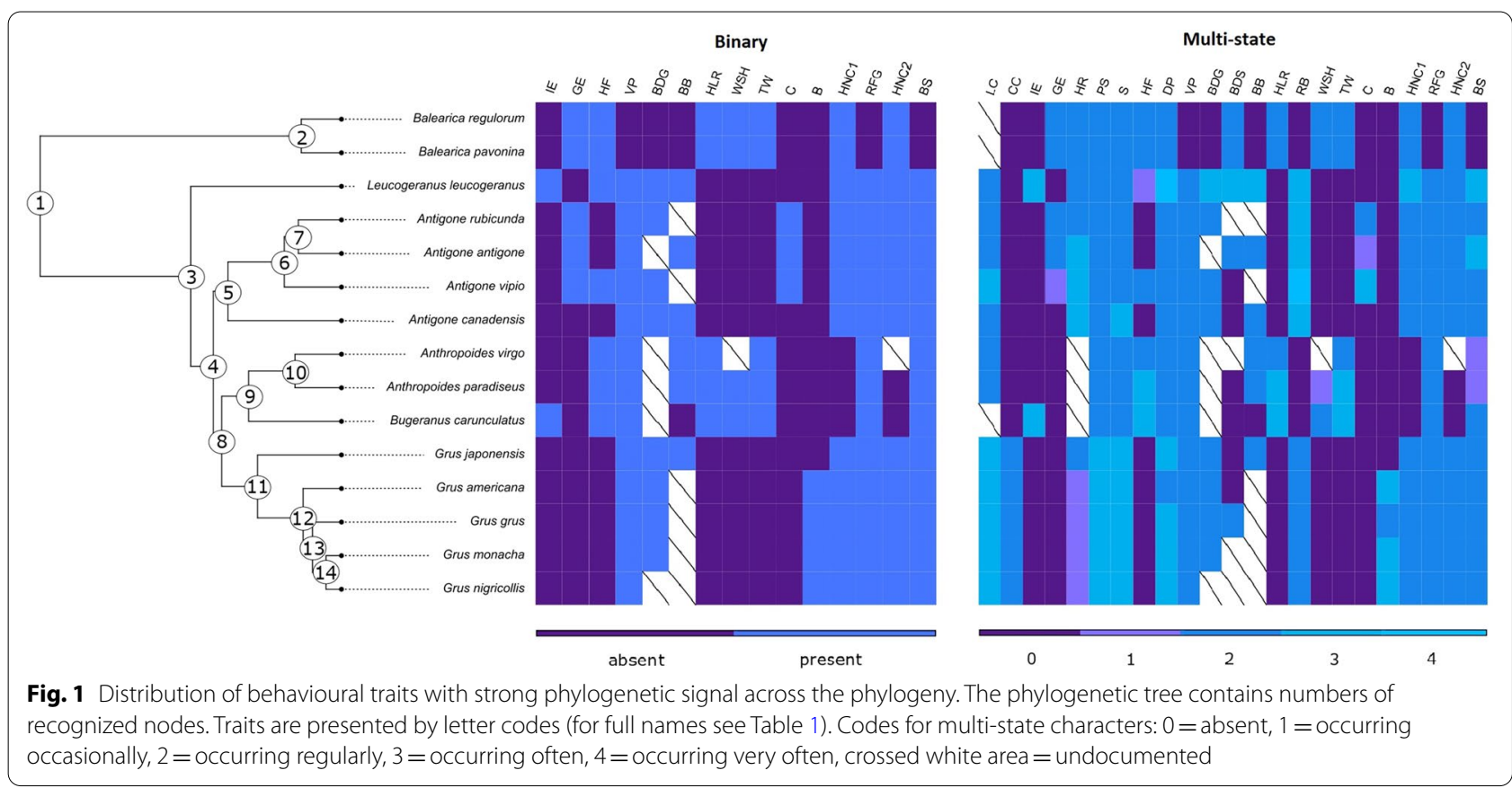


Table 1 List of studied traits with their code names, Pagel's lambda and Blomberg's $K$ values and consistency index for both multistate $(\lambda)$ and binary $(B-\lambda)$ data

\begin{tabular}{|c|c|c|c|c|c|c|c|}
\hline Display & Code name & $\lambda$ & $B-\lambda$ & $K$ & $\mathrm{~B}-\mathrm{K}$ & $\mathrm{Cl}$ & $\mathrm{B}-\mathrm{Cl}$ \\
\hline \multicolumn{8}{|l|}{ Vocalizations } \\
\hline Location call & $\mathrm{LC}$ & $\underline{0.99}$ & & 0.51 & & 0.5 & \\
\hline Copulatory call & CC & $\underline{0.99}$ & 0.48 & 0.61 & 0.61 & 1 & 1 \\
\hline \multicolumn{8}{|l|}{ Agonistic displays } \\
\hline Iris expansion & IE & $\underline{0.99}$ & $\underline{0.99}$ & 0.30 & 0.30 & 0.5 & 0.5 \\
\hline Feather tuft erection & FTE & $6 \times e^{-5}$ & & 0.37 & & 0.43 & \\
\hline Gular expansion & GE & $\underline{0.99}$ & $\underline{0.99}$ & 0.48 & 0.55 & $\underline{0.67}$ & 0.5 \\
\hline Head rub & $H R$ & $\underline{0.99}$ & & 1.31 & & $\underline{0.75}$ & \\
\hline Tertial elevation & TE & 0.87 & $5 \times e^{-5}$ & 0.57 & 0.64 & 0.5 & 0.5 \\
\hline Pre strut & PS & $\underline{0.99}$ & & 0.61 & & 1 & \\
\hline Strut & $\mathrm{S}$ & $\underline{0.99}$ & & 0.62 & & 0.5 & \\
\hline Head flick & $\mathrm{HF}$ & $\underline{0.99}$ & $\underline{0.99}$ & 0.73 & 0.57 & 0.6 & 0.33 \\
\hline Dorsal preen & $\mathrm{DP}$ & $\underline{0.99}$ & & 0.32 & & $\underline{0.67}$ & \\
\hline Ventral preen & VP & $\underline{0.99}$ & $\underline{0.99}$ & 0.35 & 0.35 & 1 & 1 \\
\hline Bill down hold & $\mathrm{BDH}$ & $6 \times e^{-5}$ & & 0.26 & & $\underline{0.67}$ & \\
\hline Bill down growl & $\mathrm{BDG}$ & $\underline{0.99}$ & $\underline{0.99}$ & 0.40 & 0.58 & 1 & 1 \\
\hline Bill down sweep & BDS & $\underline{0.99}$ & $7 \times e^{-05}$ & 0.45 & 0.49 & 0.5 & 0.33 \\
\hline Blow bubbles & $\mathrm{BB}$ & $\underline{0.99}$ & $\underline{0.99}$ & 0.24 & 0.33 & $\underline{0.67}$ & 0.5 \\
\hline Head lower ruffle & HLR & $\underline{0.99}$ & $\underline{0.99}$ & 0.81 & 0.64 & $\underline{0.67}$ & 0.5 \\
\hline Ruffle bow & $\mathrm{RB}$ & $\underline{0.99}$ & $6 \times e^{-05}$ & 0.63 & 0.64 & $\underline{0.75}$ & 0.5 \\
\hline Wing spread hold & WSH & $\underline{0.99}$ & $\underline{0.99}$ & 0.41 & 0.60 & $\underline{0.67}$ & 0.5 \\
\hline Wing spread flap & WSF & $6 \times e^{-5}$ & $6 \times e^{-05}$ & 0.54 & 0.47 & 0.33 & 0.33 \\
\hline Tail wag & TW & $\underline{0.99}$ & $\underline{0.99}$ & 0.81 & 0.64 & $\underline{0.67}$ & 0.5 \\
\hline Catapult & $\mathrm{C}$ & $\underline{0.99}$ & $\underline{0.99}$ & 0.80 & $\underline{1.39}$ & 1 & 1 \\
\hline Butterfly & B & $\underline{0.99}$ & $\underline{0.99}$ & 0.93 & 0.96 & 1 & 1 \\
\hline Hoover or neck crane & $\mathrm{HNC1}$ & $\underline{0.99}$ & $\underline{0.99}$ & $\underline{1.92}$ & $\underline{3.28}$ & $\underline{0.67}$ & 1 \\
\hline Crouch & $C R$ & 0.87 & & 0.33 & & 0.4 & \\
\hline \multicolumn{8}{|l|}{ Pair related behaviour } \\
\hline Run flap glide & RFG & $\underline{0.99}$ & $\underline{0.99}$ & 0.35 & 0.35 & 1 & 1 \\
\hline Hoover or neck crane & $\mathrm{HNC2}$ & $\underline{0.99}$ & $\underline{0.99}$ & $\underline{3.07}$ & $\underline{3.07}$ & 0.5 & 1 \\
\hline Bill stab & BS & $\underline{0.99}$ & $\underline{0.99}$ & 0.63 & 0.35 & $\underline{0.75}$ & 1 \\
\hline
\end{tabular}

Significant values are in underlined italics. Non-underlined italics are the values which are less similar than would be assumed under Brownian motion. For the calculation of Blomberg's $K$ Brownian motion model was selected for all the traits

gov/; table of access numbers of analysed species is available in Additional file 1: Table S3).

\section{Phylogenetic analysis}

Sequences were aligned in Geneious ${ }^{\circledR}$ 10.1.3 (ㄷ 2005-2017 Biomatters Ltd.) using global alignment. The best-fitting substitution model of DNA sequence evolution-the Tamura-Nei 1993 model-was selected by MEGA X [ver. 10.0.5; Kumar et al. (2018)] under the Akaike Information Criterion. Maximum likelihood and Bootstrap analyses with 10,000 replications were also conducted in MEGA X [ver. 10.0.5; Kumar et al. (2018)]. Since the topology of the phylogenetic tree of cranes was identical to the time-calibrated tree of Krajewski et al.
(2010, 2019), we used the branch lengths from Krajewski et al. (2010). Phylogenetic tree of cranes based strictly on molecular data was then imported in nexus format and paired with the matrix of behavioural traits into Mesquite ver. 3.40. History of characters was traced using likelihood methods. The same tree with branch lengths created in MEGA X was also exported into $\mathrm{R}$ version 3.5.1 (@2009-2018 RStudio, Inc). The strength of the phylogenetic signal of individual traits was evaluated by calculation of Pagel's lambda, which allows a more complex model of evolution with strong (lambda $=1$ ) to weak (lambda =0) phylogenetic covariation, and Blomberg's $K$, which is a widely used metric to test the phylogenetic signal, using the "phylosig" function in the phylosignal 
package (Keck et al. 2016). Blomberg's $K$ allows us to evaluate a strong phylogenetic signal $(K>1)$ as well as non-random diversification of trait $(K=0)$, or whether a trait evolved according to the Brownian model of evolution $(K=1)$, which means that trait evolved independently on evolution. Additionally, all the results were tested if statistically significant $(p<0.05)$. Behavioural traits were visualized on the tree by the "phylo.heatmap" function in the phytools package (Revell 2012), while the synapomorphies were mapped over the tree using the Map Characters function in the WinClada program, ver. 1.00.08 (K. Nixon॰1999-2002), which was used for basic assessment of informativeness (consistency index, hereafter abbreviated as $\mathrm{CI}$ ) of the behavioural trait subset too [also using NONA version 2.0; Goloboff (1999)]. This package was used as well to compare behavioural traits with morphological characters (cf. de Queiroz and Wimberger 1993), using the matrix compiled by Livezey (1998; specifically using his matrix from Appendix 2). The same comparisons were performed with a multistate matrix as well as with a binary matrix.

\section{Results}

\section{Phylogenetic informativeness of behavioural traits}

Firstly, all 28 possibly phylogenetically informative behavioural characters alone cannot be used for resolving species-level relationships within the Gruidae. Specifically, the strict consensus and bootstrap methods detected no supported clade within cranes. Only the majority consensus identified these six clades with stronger support: both Balearica species are grouped together in $94 \%$ of cases, Bugeranus with Antropoides with 86\%, and both these groups form one major clade with $70 \%$ support. The second major clade with 58\% support consists of Antigone canadensis, Leucogeranus and all species of the genus Grus. Inside the last group with the 78\% support Grus japonensis stands aside, while other Grus species form its sister group with $89 \%$ support. From these relationships only several subgroups are concordant with the topology based on mitochondrial genome-the subgroup comprising Balearica species, Bugeranus with Antropoides, and all species of the genus Grus (with G. japonensis sister to other Grus species) respectively.

In contrast, 48 possibly phylogenetically informative morphological characters provide higher resolution, specifically the support for Balearica, Anthropoides and Antigone vipio-rubicunda-antigone clades under the strict consensus and these groups plus Gruinae and Leucogeranus-Antigone-Grus clades under the bootstrap. The majority consensus has a full resolution identical with the original study (Fig. 5 in Livezey 1998).

Moreover, behavioural traits under phylogenetic control exhibited predominantly (82\%) a strong phylogenetic signal (Table 1) when applicated on phylogenetic tree based on genetic data. Support values for the phylogenetic tree used in the analyses are listed in Additional file 2: Table S4.

Pagel's lambda together with Blomberg's $K$ and CI for inspected behavioural traits are specified in Table 1 . The values indicate that the evolution of one third of them (e.g. Hoover or neck crane of both types or Head rub) was quite conservative and closely related to phylogeny. Traits mapped on the tree along with node numbers are shown in Fig. 1.

\section{Reconstruction of ancestral behavioural repertoire}

The reconstruction of specific behavioural trait evolution was predominantly well-resolved across the whole phylogenetic tree. The following text describes the evolution of the traits for the individual nodes. Unique changes in behaviour are displayed in Fig. 2. See detailed likelihoods of individual multi-state trait states in ancestors in Additional file 2: Table S4.

Node 1: The ancestral crane (Gruidae) appears to exhibit the following behaviour to some extent: Bare-skin-present (BSP), Bare-skin-expansion (BSE), Feather-tuft-erection (FTE), Head-rub (HR), Tertial-elevation (TE), Prestrut (PS), Strut (S), Headflick (HF), Dorsal-preen (DP), Ventral-preen (VP), Bill-down-hold (BDH), Bill-down-growl (BDG), Bill-down-sweep (BDS), Blow-bubbles (BB), Headlower-ruffle (HLR), Ruffle-bow (RB), Wing-spreadflap (WSF), Tail-wag (TW), Hoover or neck-crane of both types (HNC1 and HNC2), Crouch (CR) Runflap-glide (RFG), Bill-stab (BS), and Shading (SH).

Node 3: The ancestor of Gruinae probably exhibited Ventral-preen (VP) and Run-flap-glide (RFG), at the same intensity of performance. Tertial-elevation (TE), Bill-down-growl (BDG) and Bill-stab (BS) in different levels of intensity appear to be typical for those ancestors.

Node 5: In the common ancestor of three Antigone species (A. antigone, A. rubicunda and A. vipio) Gular-expansion (GE) and Catapult (C) appeared. Catapult is a display presented exclusively in these three species.

Node 9: The ancestor of genera Bugeranus and Anthropoides probably lost these behavioural traits: Tertial-elevation (TE), and Hoover or neck-crane of both types (HNC1 and $\mathrm{HNC2}$ ). On the contrary, Head-lower-ruffle (HLR), Wing-spread-hold (WSP), and Tail-wag (TW) likely re-appeared in this group. Node 11: All Grus species perform exclusively Copulatory call (CC). Only species of genus Grus except $G$. japonensis perform Butterfly (B). 


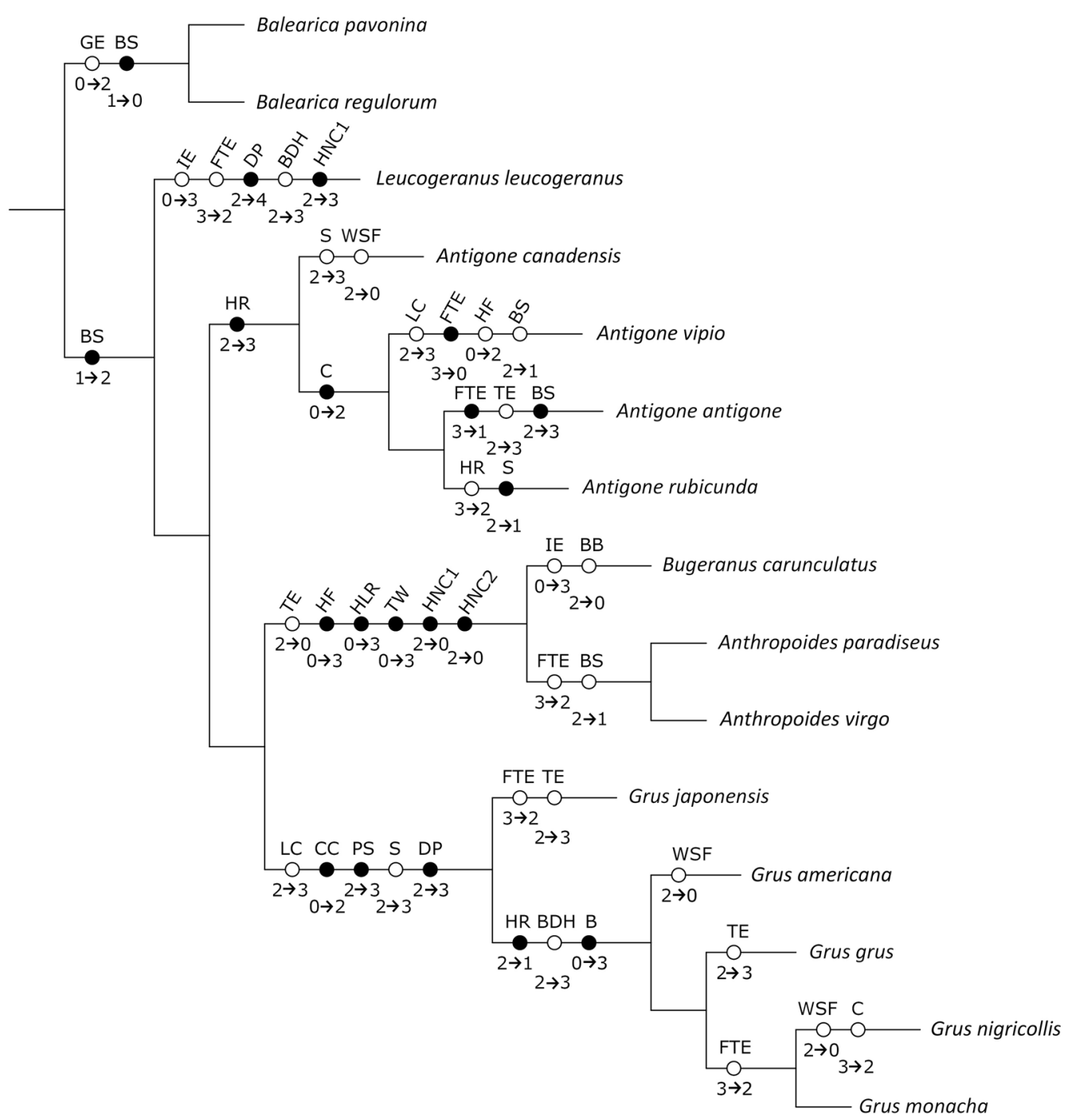

Fig. 2 Crane phylogeny based on complete mtDNA with mapped non-homoplasious (black) and homoplasious (white) a changes of multi-state behavioural characters. Traits are presented by letter codes (for full names see Table 1). Codes for multi-state characters: $0=$ absent, $1=$ occurring occasionally, 2 = occurring regularly, $3=$ occurring often, $4=$ occurring very often. Arrows indicate direction of change in specific trait (e.g. 1 to $>2$ means that trait changed in given node from occurring occasionally to occurring regularly)

In summary, ancestral cranes already exhibited quite a rich behavioural repertoire, including sophisticated epigamic behaviour, and only a minority of the traits changed during subsequent evolution.

The influence of various scoring of traits on reconstruction of ancestral behavioural repertoire and its phylogenetic informativeness

General features of phylogenetic signal and ancestral reconstruction of specific behavioural traits under the binary scoring were similar to the results obtained using the multistate coding; strong phylogenetic signal was detected in a lesser amount, i.e. $71 \%$ of traits (Table 1).
Number of changes, Pagel's lambda together with Blomberg's $K$ and $\mathrm{CI}$ for inspected behavioural traits are specified in Table 1. The evolution of traits is displayed in Fig. 3 and the traits are also mapped on the tree in Fig. 1. The reconstruction of ancestral behaviour repertoire detected these associations; see detailed likelihoods of individual traits coded binary on particular nodes in Additional file 3: Table S5.

Node 4: Bill-down-sweep (BDS) disappeared in the genera Antigone, Anthropoides, Bugeranus and Grus. Node 6: Catapult (C) and Gular-expansion appeared in genus Antigone, except for $A$. canadensis. 


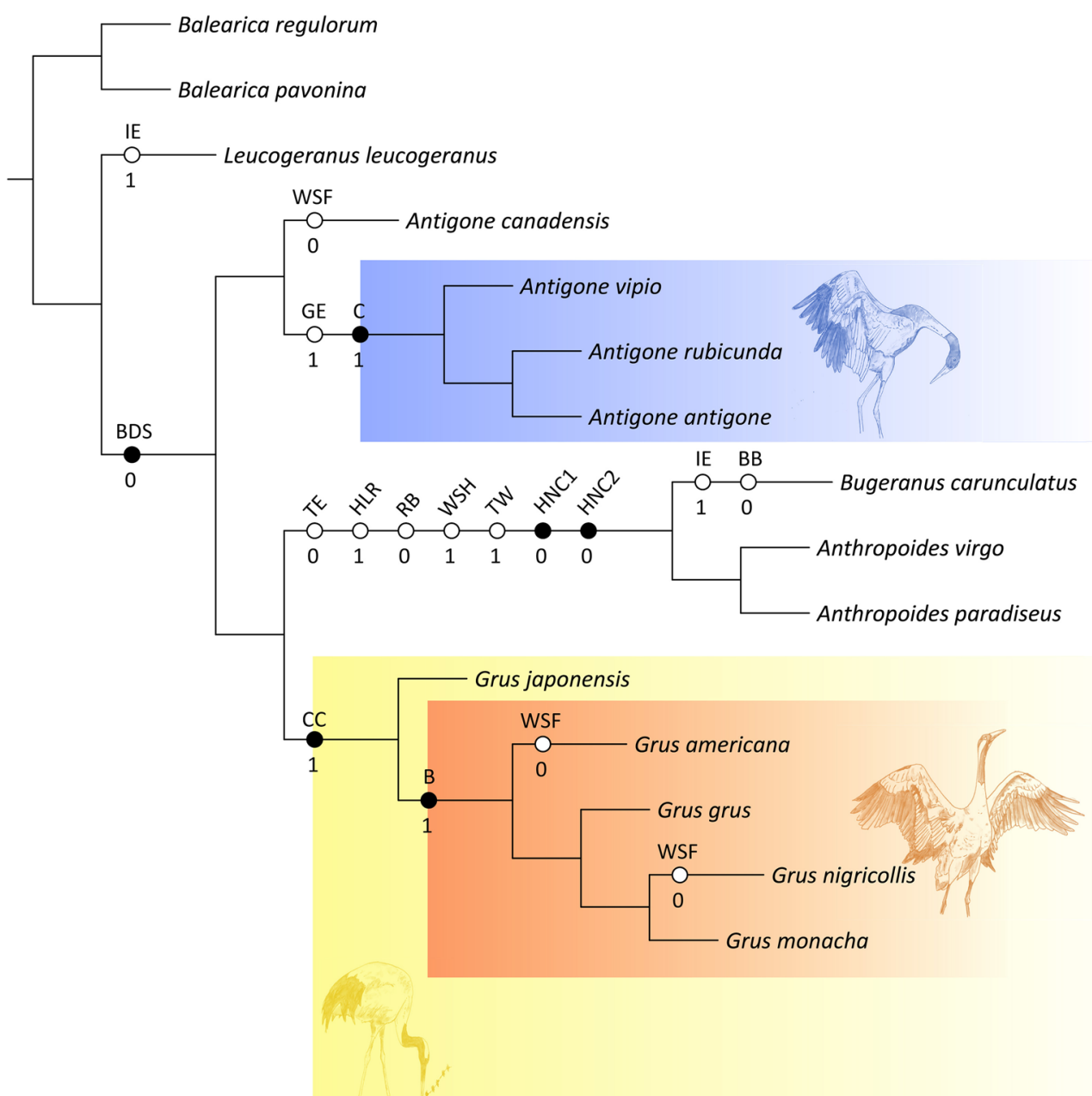

Fig. 3 Crane phylogeny based on complete mtDNA with mapped non-homoplasious (black) and homoplasious (white) changes of binary behavioural characters. Traits are presented by letter codes (for full names see Table 1). Codes for binary characters: $0=$ absent, $1=$ present

Node 9: Tertial-elevation (TE), Ruffle-bow (RB), and Hoover or neck-crane of both types ( $\mathrm{HNC1}$ and HNC2) disappeared. Head-lower-ruffle (HLR), Wing-spread-hold (WSH) and Tail-wag (TW) appeared in genera Bugeranus and Anthropoides.

Node 11: Copulatory call (CC) evolved in genus Grus.

Node 12: Butterfly (B) posture appeared in genus Grus, except for G. japonensis.

The Balearicinae did not obtain or lose any exclusive trait, but the traits in Gruinae changed as the subfamily diversified. Contrary to the multi-state data matrix, the most changes happened in the genera Bugeranus and Anthropoides.

Mean CI value for behavioural traits was 0.69 for multistate and 0.70 for binary variant. Mean CI value for morphological matrix under the same mitochondrial phylogenetic control 0.75 (binary version was not performed due the nature of traits) shows no significant difference to mean CI obtained for the multistate variant of behavioural traits ( $t$-test, $p=0.36$ ).

\section{Discussion}

Phylogenetic informativeness of behavioural traits

The present behavioural matrix with 15 crane species and 28 behavioural traits is compatible by size with many studies reviewed by de Queiroz and Wimberger (1993) in their inspection of usefulness of behaviour for phylogeny estimation. The detected level of homoplasy (mean CI value 0.69 for multistate and 0.70 for binary variants) in the behavioural traits of cranes inspected in this study seems to be rather lower than values (mean CI value 0.84 ) for similar data sets reviewed by de Queiroz and Wimberger (1993), but otherwise fully within the range of reviewed studies [CI values from 0.62 to 1 ; de 
Queiroz and Wimberger (1993)]. The level of homoplasy in inspected behavioural data is a little bit lower than in morphological data (CI 0.75), but there is no significant difference between them. Behavioural repertoire of cranes itself is not able to provide robust and reliable phylogenetic relationships, probably because of small number of phylogenetically informative traits. From all 107 identified behavioural traits (Ellis et al. 1998), only $26 \%$ (28 characters) is possibly phylogenetically informative. For comparison, from 570 morphological characters scored by Livezey (1998) only $8 \%$ (48 characters) is potentially phylogenetically informative. Nevertheless, these morphological characters provide quite robust phylogenetic relationships, which exhibit some congruence with relationships detected based on genetic data (compare Fig. 5 in Livezey 1998 with Fig. 2.1 in Krajewski 2019).

Nevertheless, in combination with genetic data, behavioural traits exhibit strong phylogenetic signal. Our findings correspond with other works according to which behavioural data carry strong phylogenetic signal and are no more homoplasious than other data sets. For example, as shown in the meta-analysis of de Queiroz and Wimberger (1993), studies of evolution on bovid behaviour (Deleporte and Cap 2014), behaviour and vocalization in deer (Cap et al. 2002, 2008), grooming behaviour in rodents (Malange et al. 2013) or social displays of the Pelecaniformes (Kennedy et al. 1996), as well as of courtship behaviour in salamanders (Arnold et al. 2017) and in seabird behaviour (Paterson et al. 1995).

The species-specific behavioural traits, albeit phylogenetically useless, might represent a type of reproductive isolation mechanism to minimize the risk of hybridization between sister or distantly related species ( $\mathrm{McCa}-$ rthy 2006). This aspect may be especially relevant for the different genera of cranes capable of hybridization, under captivity conditions as well in the wild (McCarthy 2006; Ottenburghs et al. 2015).

\section{Reconstruction of ancestral behavioural repertoire}

Reconstruction of crane ancestral behavioural repertoire indicates that complex behavioural repertoire was already present before group began to diversify. After start of diversification change of behavioural repertoire significantly slowed down with the tendency to lose traits rather than evolve new ones, e.g. Bugeranus and Anthropoides species. Even though the Balearicinae separated from Gruinae before approximately $31 \mathrm{Ma}$ (Krajewski et al. 2010; Krajewski 2019), they exhibit no special displays or even unique changes in intensity of traits. A similar pattern was recognized by Johnsgard (1983), who argued that many morphological traits present in Balearicinae are primitive for Gruidae, with Gruinae showing derived modifications. The diversification itself is imbalanced between both sister subfamilies (Krajewski et al. 2010), but that topic is itself beyond the scope of this contribution.

The most basal species of Gruinae, the Siberian Crane (Leucogeranus leucogeranus), shows the most different repertoire from all other species. However, differences are mainly in the intensity of performed display. This species otherwise exhibits biological parameters very similar to those of other crane species, except for its territorial behaviour, which is exhibited even during wintering (Johnsgard 1983).

Bugeranus and Anthropoides species as a group exhibit the most changes in behavioural repertoire both in evolution/disappearing traits and changes in frequency of performances. We are not able to explain why in this lineage the disappearing of traits occurs more often than evolution of new ones. It could be expected that the loss of traits is easier rather than de novo evolution, but in any case, it is known that the evolutionary loss might decrease costs under some selection regimes or at least might represent a nonadaptive evolutionary change (e.g. Aragón et al 1999; Beauchamp 1999; Ekman and Ericson 2006).

The Sandhill Crane (Antigone canadensis) exhibits more similarities in behavioural displays with genus Grus than with genus Antigone. This fact can imply a faster diversification within the rest of Antigone, perhaps due to dynamic demographic changes with much more regular gene flow contacts among populations of $A$. canadensis during the late Cenozoic (e.g. Wood and Krajewski 1996; Rhymer et al. 2001; Jones et al. 2005). Conversely, this similarity could be a result of ancient hybridization events [as proved e.g. in felids (Li et al. 2016) or in bovines (Wu et al. 2018) by genomic surveys].

\section{Comparison of an influence of various scoring of behavioural traits}

Since the character coding is an important issue in phylogenetic analyses (e.g. Scotland and Pennington 2000), we inspected this aspect too. The ancestral behavioural repertoires exhibited quite different scenarios to binary or multistate coding, in accordance with the results of Sansom and Wills (2013), which demonstrated that different scoring of traits could have a significant effect on results and reconstruction. A multi-state data coding approach showed more complex evolution of behaviour in cranes than the binary approach, but this is likely caused by the decrease of variability in behavioural data under the binary approach. Since the basic parameters of the level of homoplasy (CI) and phylogenetic signal were mostly similar in both approaches, we consider both scenarios as quite equivalent alternatives. 
Whereas there are minimum changes in de novo evolving and losing traits, evolution of behavioural traits in significantly more often accompanied by changes in frequency of preformation specific displays. The changes in the intensity of the traits implies that some of them evolved more rapidly, which could also represent a reproductive isolation mechanism preventing hybridization (Hendry et al. 2000 see also above) and/or some relaxed "phenotype" in newly occupied geographic regions [cf. dispersal phenotype sensu Geist (1987)].

In future research it might be also useful to compare wider spectrum of different statistical approaches [e.g. maximum parsimony versus Bayesian phylogenetic inference using Lewis's Mk model; Schrago et al. (2018), Spade (2020), Varga et al. (2020), see also Goloboff et al. (2019)] to identify the best supported evolution of behavioural traits.

\section{Conclusions}

Our results suggest that behaviour reflects phylogeny in cranes. The behavioural data of living species gives us the opportunity to decipher evolutionary history of crane in promising details. Considering the well-compiled morphological, behavioural and molecular datasets for cranes (Ellis et al. 1998; Livezey 1998; Krajewski et al. 2010; Panov et al. 2010; Krajewski 2019) the complete sociogram of the Limpkin is the most important facet for the final understanding of the evolution of behaviour cranes and their closest relatives.

\section{Supplementary Information}

The online version contains supplementary material available at https://doi. org/10.1186/s40657-021-00275-4.

Additional file 1: Table S1. Compressed description of used behavioura traits. Table S2. Behavioural traits. Table S3. GenBank access numbers of analysed species. Figure S1. Node support values for the phylogenetic tree.

Additional file 2: Table S4. Likelihoods reconstructions of individual traits for particular nodes based on multi-state matrix.

Additional file 3: Table S5. Likelihoods reconstructions of individual traits for particular nodes based on binary matrix.

\section{Acknowledgements}

We are very grateful to Carey Krajewski for helpful advice on the mitochondrial data of cranes, Pavel Duda for valuable discussions of methods and results, Anton Baer for English editing, and the editor and two anonymous reviewers for very valuable comments which improved the manuscript significantly.

\section{Authors' contributions}

NN and JR conceived the idea; NN created a data matrix from existing data sources, performed the analysis and led the writing. Both JR and NN contributed significantly to the final version. Both authors read and approved the final manuscript.

\section{Funding}

This work was financially supported by the grant agency of the University of South Bohemia (04-048/2019/P).

\section{Availability of data and materials}

The data matrix and access numbers to genetic material on GenBank are available in additional files; other data subsets used and/or analysed during this study are available from the corresponding author on request.

\section{Declarations}

Ethics approval and consent to participate

Not applicable.

\section{Consent for publication}

Not applicable.

\section{Competing interests}

The authors declare that they have no competing interests.

Received: 25 September 2020 Accepted: 13 July 2021

Published online: 30 July 2021

\section{References}

Aragón S, Møller AP, Soler JJ, Soler M. Molecular phylogeny of cuckoos supports a polyphyletic origin of brood parasitism. J Evol Biol. 1999;12:495-506

Archibald GW. Crane taxonomy as revealed by the unison call. Proceedings of the international crane workshop. Stillwater: Oklahoma State University. 1976;1:225-51.

Arnold SJ, Kiemnec-Tyburczy KM, Houck LD. The evolution of courtship behavior in plethodontid salamanders, contrasting patterns of stasis and diversification. Herpetologica. 2017;73:190-205.

Beauchamp $\mathrm{G}$. The evolution of communal roosting in birds: origin and secondary losses. Behav Ecol. 1999;10:675-87.

Blomberg SP, Garland T Jr, Ives AR. Testing for phylogenetic signal in comparative data: behavioral traits are more labile. Evolution. 2003;57:717-45.

Boast AP, Chapman B, Herrera MB, Worthy TH, Scofield RP, Tennyson AJD, et al. Mitochondrial genomes from New Zealand's extinct adzebills (Aves: Aptornithidae: Aptornis) support a sister-taxon relationship with the AfroMadagascan Sarothruridae. Diversity. 2019;11:24.

Bryan DC, Kirwan GM. Limpkin (Aramus guarauna). In: del Hoyo J, Elliott A, Sargatal J, Christie DA, de Juana E, editors. Handbook of birds of the world alive. Barcelona: Lynx Edici; 2018. p. 1-4.

Cap H, Aulagnier S, Deleporte P. The phylogeny and behaviour of Cervidae (Ruminantia Pecora). Ethol Ecol Evol. 2002;14:199-216.

Cap H, Deleporte P, Joachim J, Reby D. Male vocal behavior and phylogeny in deer. Cladistics. 2008;24:917-31.

de Queiroz A, Wimberger PH. The usefulness of behavior for phylogeny estimation: levels of homoplasy in behavioral and morphological characters. Evolution. 1993;47:46-60.

Deleporte P, Cap H. Behavioural phylogeny of Bovidae. Zitteliana B. 2014;32:175-84.

Dinets V. Crane dances as play behaviour. Ibis. 2013;155:424-5.

Downs CT, Bredin IP, Wragg PD. More than eating dirt: a review of avian geophagy. Afr Zool. 2019;54:1-19.

Duda P, Zrzavý J. Evolution of life history and behavior in Hominidae: towards phylogenetic reconstruction of the chimpanzee-human last common ancestor. J Hum Evol. 2013;65:424-46.

Ekman J, Ericson PGP. Out of Gondwanaland; the evolutionary history of cooperative breeding and social behaviour among crows, magpies, jays and allies. Proc R Soc B Biol Sci. 2006;273:1117-25.

Ellis DH, Swengel SR, Archibald GW, Kepler CB. A sociogram for the cranes of the world. Behav Process. 1998:43:125-51.

Ericson PGP, Irestedt M, Nylander JAA, Christidis L, Joseph L, Qu Y. Parallel evolution of bower-building behavior in two groups of bowerbirds suggested by phylogenomics. Syst Biol. 2020;69:820-9.

Fain MG, Krajewski C, Houde P. Phylogeny of "core Gruiformes" (Aves: Grues) and resolution of the Limpkin-Sungrebe problem. Mol Phylogenet Evol. 2007:43:515-29. 
Ganslosser U. Stages in formation of social relationships-an experimental investigation in kangaroos (Macropodoidea: Mammalia). Ethology. 1993:94:221-47.

Gansloßer U. Courtship behaviour in Macropodoidea (kangaroos, wallabies and rat kangaroos) _ phylogenetic and ecological influences on ritualization. Mammal Rev. 1995;25:131-57.

García-R JC, Gibb GC, Trewick SA. Eocene diversification of crown group rails (Aves: Gruiformes: Rallidae). PLoS ONE. 2014;9:e109635.

Gatesy J, Milinkovitch M, Waddell V, Stanhope M. Stability of cladistic relationships between Cetacea and higher-level artiodactyl taxa. Syst Biol. 1999:48:6-20.

Gaubert P, Wozencraft WC, Cordeiro-Estrela P, Veron G. Mosaics of convergences and noise in morphological phylogenies: what's in a viverridlike carnivoran? Syst Biol. 2005;54:865-94.

Geist V. On speciation in Ice Age mammals, with special reference to cervids and caprids. Can J Zool. 1987;65:1067-84

Goloboff PA. NONA ver. 2.0. 2002. Tucumán, Argentina: published by the author. 1999. p. 45-111.

Goloboff PA, Pittman M, Pol D, Xu X. Morphological data sets fit a common mechanism much more poorly than DNA sequences and call into question the Mkv model. Syst Biol. 2019;68:494-504.

Gong J, Zhao R, Huang Q, Sun X, Huang L, Jing M. Two mitogenomes in Gruiformes (Amaurornis akool/A. phoenicurus) and the phylogenetic placement of Rallidae. Genes Genom. 2017;39:987-95.

Harris J, Mirande C. A global overview of cranes: status, threats and conservation priorities. Chin Birds. 2013;4:189-209.

Hemmer H. Untersuchungen zur stammesgeschichte der Pantherkatzen (Pantherinae). Veröff Zool Staatssamml München. 1966;11:111-21.

Hendry AP, Wenburg JK, Bentzen P, Volk EC, Quinn TP. Rapid evolution of reproductive isolation in the wild: evidence from introduced salmon. Science. 2000;290:516-8.

IUCN. The IUCN Red List of Threatened Species. Version 2021-1. 2021. https://www.iucnredlist.org. Accessed 20 Feb 2021.

Johnsgard PA. Evolutionary trends in the behaviour and morphology of the Anatidae. Wildfowl Trust Tenth Annu Rep. 1962:13:130-48.

Johnsgard PA. Handbook of waterfowl behavior. Ithaca: Cornell University Press; 1965.

Johnsgard PA. Cranes of the world. Bloomington: Indiana University Press; 1983.

Jones KL, Krapu GL, Brandt DA, Ashley MV. Population genetic structure in migratory sandhill cranes and the role of Pleistocene glaciations. Mol Ecol. 2005;14:2645-57.

Keck F, Rimet F, Bouchez A, Franc A. Phylosignal: an R package to measure, test, and explore the phylogenetic signal. Ecol Evol. 2016;6:2774-80.

Kennedy M, Spencer HG, Gray RD. Hop, step and gape: do the social displays of the Pelecaniformes reflect phylogeny? Anim Behav. 1996;51:273-91.

Krajewski C. Phylogenetic taxonomy of cranes and the evolutionary origin of the whooping crane. In: Nyhus PJ, French JB, Converse SJ, Austin $J$ E, Delap JH, editors. Whooping cranes: biology and conservation. Biodiversity of the world: conservation from genes to landscapes. Cambridge: Academic Press; 2019. p. 17-24.

Krajewski C, Sipiorski JT, Anderson FE. Complete mitochondrial genome sequences and the phylogeny of cranes (Gruiformes: Gruidae). Auk. 2010;127:440-52.

Kumar S, Stecher G, Li M, Knyaz C, Tamura K. MEGA X: molecular evolutionary genetics analysis across computing platforms. Mol Biol Evol. 2018:35:1547-9.

Kusmierski R, Borgia G, Uy A, Grozier RH. Labile evolution of display traits in bowerbirds indicates reduced effects of phylogenetic constraint. Proc R Soc B Biol Sci. 1997;264:307-13.

Lefebvre L, Ducatez S, Audet JN. Feeding innovations in a nested phylogeny of Neotropical passerines. Philos Trans R Soc B Biol Sci. 2016:371:20150188.

Leyhausen P. Katzen - eine Verhaltenskunde. 5th ed. Berlin und Hamburg: Verlag Paul Parey; 1979.

Li G, Davis BW, Eizirik E, Murphy WJ. Phylogenomic evidence for ancient hybridization in the genomes of living cats (Felidae). Genome Res. 2016;26:1-11.
Ligon RA, Diaz CD, Morano JL, Troscianko J, Stevens M, Moskeland A, et al. Evolution of correlated complexity in the radically different courtship signals of birds-of-paradise. PLoS Biol. 2018;16:e2006962.

Lister AM. Behavioural leads in evolution: evidence from the fossil record. Biol J Linn Soc. 2014:112:315-31.

Livezey BC. A phylogenetic analysis and classification of recent dabbling ducks (Tribe Anatini) based on comparative morphology. Auk. 1991;108:471-507.

Livezey BC. A phylogenetic analysis of the Gruiformes (Aves) based on morphological characters, with an emphasis on the rails (Rallidae). Philos Trans R Soc Lond B Biol Sci. 1998;353:2077-151.

Lorenz K. Vergleichende Bewegungsstudien an Anatinen. J Ornithol. 1941:89:194-294.

Malange J, Alberts CC, Oliveira ES, Japyassú HF. The evolution of behavioural systems: a study of grooming in rodents. Behaviour. 2013;150:1295-324.

Mattern MY, McLennan DA. Phylogeny and speciation of felids. Cladistics. 2000;16:232-53.

McCarthy EM. Handbook of avian hybrids of the world. Oxford: Oxford University Press; 2006

McLennan DA, Mattern MY. The phylogeny of the Gasterosteidae: combining behavioral and morphological data sets. Cladistics. 2001;17:11-27.

Miles MC, Fuxjager MJ. Phenotypic diversity arises from secondary signal loss in the elaborate visual displays of toucans and barbets. Am Nat. 2019;194:152-67.

Ottenburghs J, Ydenberg RC, van Hooft P, van Wieren SE, Prins HHT. The avian hybrids project: gathering the scientific literature on avian hybridization. Ibis. 2015;157:892-4.

Panov EN, Pavlova EY, Nepomnyashchikh VA. Signal behavior in cranes (the Siberian Crane Sarcogeranus leucogeranus, the White-naped Crane Grus vipio, and the Red-crowned Crane Grus japonensis) in the context of the ritualization hypothesis. Biol Bull. 2010;37:915-40.

Paterson AM, Wallis GP, Gray RD. Penguins, Petrel, and parsimony: does cladistic analysis of behavior reflect seabird phylogeny? Evolution. 1995:49:974-89.

Penndorf J, Aplin L. Environmental and life history factors, but not age, influence social learning about food: a meta-analysis. Anim Behav. 2020;167:161-76.

Prange H. Die Welt der Kraniche: Leben-Umfeld-Schutz: Verbreitung aller 15 Arten. Germany: Martin-Luther-Universität Halle-Wittenberg; 2016.

Price JJ, Clapp MK, Omland KE. Where have all the trees gone? The declining use of phylogenies in animal behaviour journals. Anim Behav. 2011:81:667-70.

Prum RO. Phylogenetic analysis of the evolution of display behavior in the Neotropical manakins (Aves: Pipridae). Ethology. 1990;84:202-31.

Prum RO. Phylogenetic analysis of the evolution of alternative social behavior in the manakins (Aves: Pipridae). Evolution. 1994;48:1657-75.

Prum RO. Sexual selection and the evolution of mechanical sound production in manakins (Aves: Pipridae). Anim Behav. 1998;55:977-94.

Prum RO, Berv JS, Dornburg A, Field DJ, Townsend JP, Lemmon EM, et al. A comprehensive phylogeny of birds (Aves) using targeted next-generation DNA sequencing. Nature. 2015;526:569-73.

Rendall D, Di Fiore A. Homoplasy, homology, and the perceived special status of behavior in evolution. J Hum Evol. 2007:52:504-21.

Revell LJ. phytools: an R package for phylogenetic comparative biology (and other things). Method Ecol Evol. 2012;3:217-23.

Rhymer JM, Fain MG, Austin JE, Johnson DH, Krajewski C. Mitochondrial phylogeography, subspecific taxonomy, and conservation genetics of sandhill cranes (Grus canadensis; Aves: Gruidae). Conserv Genet. 2001;2:203-18.

Sansom RS, Wills MA. Fossilization causes organisms to appear erroneously primitive by distorting evolutionary trees. Sci Rep. 2013;3:2545.

Scholes E III. Evolution of the courtship phenotype in the bird of paradise genus Parotia (Aves: Paradisaeidae): homology, phylogeny, and modularity. Biol J Linn Soc. 2008;94:491-504.

Schrago CG, Aguiar BO, Mello B. Comparative evaluation of maximum parsimony and Bayesian phylogenetic reconstruction using empirical morphological data. J Evol Biol. 2018;31:1477-84.

Scotland RW, Pennington RT. Homology and systematics: coding characters for phylogenetic analysis. Systematics association special volumes. Los Angeles: CRC Press; 2000.

Scotland RW, Olmstead RG, Bennett JR. Phylogeny reconstruction: the role of morphology. Syst Biol. 2003;52:539-48. 
Senter P. Voices of the past: a review of Paleozoic and Mesozoic animal sounds. Hist Biol. 2008;20:255-87.

Spade DA. An extended model for phylogenetic maximum likelihood based on discrete morphological characters. Stat Appl Genet Mol Biol. 2020;19:20190029.

Sunquist M, Sunquist F. Wild cats of the world. Chicago: The University of Chicago Press; 1996.

Takeda KF, Hiraiwa-Hasegawa M, Kutsukake N. Duet displays within a flock function as a joint resource defence signal in the red-crowned crane. Behav Ecol Sociobiol. 2018;72:66

Takeda KF, Hiraiwa-Hasegawa M, Kutsukake N. Uncoordinated dances associated with high reproductive success in a crane. Behav Ecol. 2019;30:101-6.

Varga Z, Ronkay G, Nagy J, Ronkay L. Contribution to the taxonomy and phylogeny of the genus Polia Ochsenheimer, 1816 (Noctuidae, Noctuinae,
Hadenini): species groups and pairs in the Holarctic subgenus Polia s. str. Acta Zool Acad Sci H. 2020;66:35-67.

Vrba ES, Schaller GB. Antelopes, deer, and relatives. New Haven: Yale University Press; 2000

Walther FR. Communication and expression in hoofed mammals. Bloomington: Indiana University Press; 1984.

Wood TC, Krajewski C. Mitochondrial DNA sequence variation among the subspecies of Sarus Crane (Grus antigone). Auk. 1996;113:655-63.

Wu DD, Ding XD, Wang S, Wójcik JM, Zhang Y, Tokarska M, et al. Pervasive introgression facilitated domestication and adaptation in the Bos species complex. Nat Ecol Evol. 2018;2:1139-45.
Ready to submit your research? Choose BMC and benefit from:

- fast, convenient online submission

- thorough peer review by experienced researchers in your field

- rapid publication on acceptance

- support for research data, including large and complex data types

- gold Open Access which fosters wider collaboration and increased citations

- maximum visibility for your research: over $100 \mathrm{M}$ website views per year

At BMC, research is always in progress.

Learn more biomedcentral.com/submissions 